\title{
The promise of engagement
}

\author{
John P. Meyer and Benjamin Schneider
}

Few topics have captured the attention of both the academic and consulting communities like employee engagement. Although popularized by human resources consulting firms in the early 2000s (Macey \& Schneider, 2008), the term "engagement" was first introduced to the academic literature by William Kahn in a 1990 Academy of Management Journal article. It has since been the subject of considerable research by both academics and practitioners. With the odd exception (e.g., Harter et al., 2002, 2020), research conducted within organizations or by consulting firms has been proprietary, so that our shared knowledge about engagement comes largely from the academic literature. Indeed, academic scholars have been prolific in their theorizing and research on the topic. This work has been summarized and critiqued in numerous books (e.g., Albrecht, 2010; Bakker \& Leiter, 2010; Truss et al., 2009), special issues (Bakker \& Albrecht, 2018; Shantz, 2017), narrative review articles (e.g., Bakker et al., 2014; Macey \& Schneider, 2008; Saks \& Gruman, 2014), and meta-analyses (e.g., Christian et al., 2011; Crawford et al., 2010; Halbesleben, 2010; Knight et al., 2016; Mackay et al., 2017; Young et al., 2018). So - bottom line - we have learned a great deal about engagement over the last few decades.

This book is about more than what we know about engagement; it is also about what we still need to know, and how we might go about learning more. It is about providing a research agenda set forth by the experts who have contributed much of what we have learned to date. It identifies important unanswered questions to stimulate those interested in beginning or advancing their own research on engagement. It is also about recent advances in methodology and data analytic techniques that can be used to address many of the unanswered questions, and stimulate still others.

To set the stage for what is to come, we first provide some context, starting with the basic questions: "What is engagement?"; "How is it measured?"; "How does it develop?"; "Why is it important?" Again, given the breadth of theory, research, and practical application, we can only scratch the surface here. Readers are encouraged to consult the more detailed reviews described above 
for more detail. In addition, of course, the authors of each of the chapters in this book provide specific background as a basis for the research agenda they propose. So, as readers will see, the chapters in the book are about specific issues with regard to engagement research (facets of engagement, outcomes from engagement, multi-level issues in engagement research, and so forth) but here we introduce the reader to the broad engagement topic and its research history.

\section{Background}

\section{What is engagement?}

Although we typically recognize engagement when we see it, coming to a consensus on a precise definition of engagement is more difficult. There are several reasons for this, but arguably one of the most important is the background and perspective of the theorists who have been instrumental in popularizing the concept. For example, for Kahn (1990) the notion of engagement emerged from extensive observation and interviews with employees in two quite diverse organizations. Based on this research, Kahn defined engagement as "the harnessing of organizational members' selves to their work roles; in engagement, people employ and express themselves physically, cognitively, and emotionally during role performances" (p. 694). In contrast, for another international team of researchers, interest in engagement grew out of an earlier program of research on burnout (Bakker \& Demerouti, 2017; Demerouti et al., 2001). Due in part to the positive psychology movement and its emphasis on well-being as opposed to ill-being (e.g., Seligman \& Csikszentmihalyi, 2000, 2014), engagement was viewed as the antipode to burnout, and was defined as "as a positive, fulfilling, work-related state of mind that is characterized by vigor, dedication, and absorption" (Schaufeli \& Bakker, 2004, p. 295). Still others working through the lens of self-determination theory (SDT; Deci \& Ryan, 2000; Gagné \& Deci, 2005), considered engagement to be synonymous with autonomous (self-determined) motivation (e.g., Meyer et al., 2010).

Another complicating factor is the fact that engagement can be viewed as a personal disposition (trait engagement), a psychological state (state engagement), or as a set of behaviors (behavioral engagement; Macey \& Schneider, 2008). The definitions offered earlier by founders of this engagement endeavor tend to focus on the "state of being engaged," and set the stage for a program of research to identify personal (state engagement) and situational factors that 
contribute to (dis)engagement, as well as the outcomes (behavioral engagement) likely to result. We summarize some of this research later.

A third complicating factor in defining engagement concerns the target of engagement. We started this chapter by making reference to "employee engagement," and indeed this is a term that is commonly used because it locates the engagement within the person. However, other commonly used terms, such as "work engagement" and "job engagement," focus more on the setting in which the engagement is expressed. But engagement can also be described with reference to more specific targets to which it is addressed, such as "task engagement," “organizational engagement," "team engagement," or "project engagement," to name but a few.

A final complication is the need to distinguish engagement from related concepts such as job satisfaction, affective organizational commitment, and job involvement (see Meyer, 2017). Some scholars have argued that these concepts all reflect a common underlying positive attitude, or "A factor" (Newman et al., 2010), but others have provided meta-analytic evidence for the distinctiveness of the constructs (Christian et al., 2011). The conceptual overlap with other constructs is not limited to state engagement, but applies also to trait and behavioral engagement (Macey \& Schneider, 2008). The key attraction of the engagement construct is its focus on energy, activation, and arousal. Regardless of the specific measures used to assess it, they all get at pieces of these. Further, analyses regarding outcomes reveal that engagement makes a significant incremental contribution to the prediction of employee effectiveness (Mackay et al., 2017).

\section{How is engagement measured?}

Just as there are multiple definitions of engagement, so too are there multiple measures. Two such measures were developed to reflect Kahn's (1990) definition, with subscales measuring cognitive, affective, and behavioral engagement (May et al., 2004; Rich et al., 2010). The most widely used measure in the academic literature is the Utrecht Work Engagement Scale (UWES: Schaufeli et al., 2002). Consistent with the earlier definition of Schaufeli and Bakker (2004), the UWES includes three subscales: vigor, dedication, and absorption. Other measures have been developed to reflect engagement to specific targets including the job and organization (Saks, 2006), and work and family (Rothbard, 2001).

The foregoing measures are generally completed by employees and the scores are linked to other variables of interest at an individual level of analysis. 
However, these individual scores are sometimes aggregated to higher levels when researchers are interested in team, unit, or organizational engagement (e.g., Harter et al., 2002; Schneider et al., 2017). Alternatively, authors may use a "referent shift" (Chan, 1998) by rewording the items to refer to employees in the team or organization rather than the individual employee (e.g., Barrick et al., 2015). Items can also be reworded to measure engagement at "lower levels," such as a specific task or engagement at a specific time (e.g., Bakker \& Bal, 2010; Bledow et al., 2011; Sonnentag, 2003). As discussed later, and elsewhere in this book, these adaptations of the engagement measures allow for higherand cross-level analyses.

\section{How does engagement develop?}

Not surprisingly, this is also a complex question, and the answers depend on the theoretical framework guiding the research. One of the most well-established theories used to explain the development of engagement is the Job Demands-Resources (JD-R) model (Bakker \& Demerouti, 2007, 2017). Job demands are the physical, psychological, social, and organizational aspects of the job that require sustained effort, and were initially considered to contribute to burnout (Demerouti et al., 2001). By contrast, resources are physical, psychological, social, and organizational aspects of the job that help to meet demands and contribute to engagement. However, it is now recognized that some demands can also contribute to engagement by stimulating the use of job and personal resources. The JD-R model has served as the impetus for a large body of engagement research (see Bakker \& Demerouti, 2017) and is addressed in more detail in subsequent chapters.

SDT has also been a major impetus for engagement research and has been integrated within the JD-R model to elaborate on the mechanisms by which job resources contribute to engagement (e.g., Bakker \& Demerouti, 2017; Schaufeli \& Taris, 2014). According to SDT, employees are more likely to be engaged when conditions are conducive to the satisfaction of three core psychological needs: autonomy, competence, and relatedness. Thus, rather than focusing on specific conditions that contribute to the development of engagement, SDT offers need satisfaction as a "basic principle" underlying the engagement process (Meyer, 2013). There are many other well-established principles that can also be used to explain, or predict, the implications of specific interventions on employee engagement. These include, but are not limited to, person-environment fit, organizational support, trust, and justice. 


\section{Why does engagement matter?}

The answer to this question is key to the strong interest in engagement among both academics and practitioners. Since the term was introduced by Kahn (1990), the "promise of engagement" was a motivated, happier, healthier, and more productive workforce. Evidence for these positive outcomes is provided by the findings reported in several meta-analyses (e.g., Christian et al., 2011; Crawford et al., 2010; Halbesleben, 2010; Mackay et al., 2017). Indeed, engagement has been consistently and significantly linked to job performance, absenteeism, retention, and well-being. Moving beyond the individual level of analysis, there is also evidence linking engagement to effectiveness at the team (Costa et al., 2014a, 2014b) and organizational (Barrick et al., 2015; Schneider et al., 2017) levels.

Of course, all of this evidence must be considered in context. Among other things, as we noted earlier, there remains some disagreement about the meaning and measurement of engagement. Most of the meta-analytic evidence for the positive outcomes associated with engagement comes from individual-level studies of "work engagement" measured at a single point in time. There are exceptions, but they are relatively rare. Higher- and cross-level studies are also relatively rare, as are diary and longitudinal studies, and studies focusing on engagement with other targets (e.g., tasks; projects). Questions also remain about the potential "dark side" of engagement (e.g., links to workaholism; work interfering with family). And perhaps most importantly, we cannot be sure that the promise of engagement will hold under the conditions of change in work, workers, and working that we will encounter in the coming decades. This book is about the future of engagement research, and the following is a brief roadmap to guide you through the chapters that follow.

\section{A roadmap}

\section{Part I: Expanding traditional perspectives on engagement}

The chapters in Part I address many of the ways that future research might expand upon the traditional perspectives on engagement just described. In Chapter 2, Alan Saks notes that the vast majority of engagement research has focused on job/work engagement with the employee as a referent (i.e., individual employees report on their own level of engagement with their job or work). This research has generated a wealth of information with practical implications. However, there are many other potential targets of engagement, and these can be measured from multiple perspectives. Saks offers a 
multidimensional model of engagement with five targets (tasks, job, team, business unit, and organization) and four referents (individual, team, unit, and organization). Thus, employees can be asked to what extent they or their team/ unit/organization members are engaged with their tasks, job, team, unit, or organization. Expanding the construct of engagement in this way raises a wide range of research questions pertaining to the measurement of engagement, the nomological network of antecedents and outcomes within targets, and relations among the various targets and referents.

In Chapter 3, Despoina Xanthopoulou and Arnold Bakker similarly argue for expansion of engagement research across levels. Working primarily within the JD-R theory framework (Bakker \& Demerouti, 2017), they review research using the UWES at the stable individual level (i.e., across time) and adapted to the situational (time-delimited) and team/organizational levels. Again, raising the possibility that engagement is dynamic (i.e., can vary across time and situations) and can be operationalized at higher levels (e.g., team, organization) opens the door to a wide range of new questions. Xanthopoulou and Bakker focus particularly on the questions of isomorphism (similarity) in the antecedents and consequences of engagement at different levels and the processes that link engagement, its antecedents, and outcomes, across levels.

Perhaps attesting to its importance, Marisa Salanova also addresses engagement from a multi-level perspective in Chapter 4 . She views engagement from a positive psychology perspective as an indicator of well-being at the individual, team, and organization levels. Using the HEalthy, Resilient Organization (HERO) model (Salanova et al., 2012) as a point of departure, she reviews research illustrating how healthy organizational resources and practices contribute to healthy employees (including engagement) and, in turn, to healthy organizational outcomes. Salanova places particular emphasis on her program of intervention research. While the findings have been largely supportive of the HERO Model, she identifies several new directions for research. To give but one example, she notes that interventions often have significant positive effects in the short term, but decline in the longer term. She calls for more research to identify strategies (e.g., designating well-being champions) that can be used to maintain and build upon initial gains.

Leaetta Hough and Frederick Oswald call for expansion of engagement research in a very different direction in Chapter 5. Most notably, they call for greater emphasis on the role of individual differences, particularly personality, in understanding the engagement process. They review research linking personality (e.g., Big 5 dimensions; core self-evaluation) to work engagement, proposing that they might serve as indicators of engagement propensity that 
can be incorporated into organizational selection systems. In this regard, they call for more research looking at facets of the Big 5 traits as general or situation-specific predictors of engagement. In a particularly unique twist to the individual-differences perspective, they note that the personality of leaders and co-workers might predict the engagement of those around them. Although they present some evidence to support this contagion effect (see also the Xanthopoulou and Bakker, and Salanova chapters), they argue for a much more systematic program of research using more sophisticated methodology and analytic techniques. Moreover, they call for greater use of follower engagement as a criterion in the evaluation of leader effectiveness.

Jonathon Halbesleben rounds out Part I of the book in Chapter 6 by expanding on the variety of potential outcomes of engagement. Not surprisingly, considerable attention has been given to the implications of employee engagement on retention and job performance, but there are many other potential outcomes that warrant investigation, including job crafting, innovation, creativity, safety and well-being, and work-life boundaries. Halbesleben uses conservation of resources theory (Hobfoll, 1989) to explain how and why engagement leads to these outcomes, as well as how the outcomes can in turn contribute to enhanced engagement to create a positive gain cycle. However, he also notes that there might be a "dark side" to engagement if, for example, it leads to excess emphasis on work to the detriment of work-life balance, or to "cutting corners" in the interests of efficiency with accompanying increases in risks to safety. Halbesleben suggests that one potential solution to the latter problem might be to foster engagement with the outcome-specific behaviors themselves (e.g., safety behaviors). This is in line with, and extends, the argument made by Saks for expansion of the targets of engagement, and is one of many of the directions for future research that he recommends.

\section{Part II: Conceptualizing engagement in the changing world of work}

While the chapters in Part I expand the concept of engagement in somewhat traditional ways, the chapters in Part II address the future of engagement theory, research, and practice in the changing world of work.

In Chapter 7, Peter Cappelli and Liat Eldor note that most engagement theory and research is premised on the notion of "standard employment" arrangements. However, there is a small, but increasing, percentage of individuals engaged in "gig" or contract work in its various shapes and sizes. Relationships between contractors and their clients are quite different from those between employers and employees, and are indeed regulated by contract law rather than employment law. These differences have implications for the meaning 
of engagement, what organizations (clients) might expect as a consequence of contract worker engagement, and what they can do to foster it. For example, as noted earlier, much of the theory and research pertaining to engagement deals with "work" or "job" engagement, both of which can have quite different meaning for standard employees and contract workers. Similarly, a common expectation for the engaged employee is that they will "go above and beyond" in the best interests of the employer, but the outcomes required of contractor workers are defined by the terms of the contract and any deviations may be neither expected nor desired. Finally, many of the initiatives that organizations might introduce to engage their employees (e.g., empowerment, training, mentoring) are either not relevant or may be in violation of contract law. However, rather than abandoning the construct as irrelevant for contract workers, Cappelli and Eldor suggest new ways of thinking about (a) the meaning of engagement for contract workers, (b) ways to foster such engagement, and (c) the benefits of doing so for both the contract worker and the client. These issues will become of increasing importance as contract work becomes more prevalent, but they have yet to be addressed systematically in theory, let alone research.

In addition to the changing employment relationships discussed by Cappelli and Eldor, work is increasingly being automated. In Chapter 8, John Boudreau discusses how both changing relationships and automation will create the need for continual "deconstruction and reinvention" of work. This process of deconstruction and reinvention involves the identification of "work elements" that make up a job. Once identified, decisions must be made about whether, and how, these elements should be automated or assigned to humans in standard and/or non-standard work arrangements. Importantly, these decisions are not of the either/or variety, but might include varying combinations of humans and automation. For example, some work elements might best be automated whereas others can only be performed by humans. In other cases, rather than "replacing" humans, automation might be used to "augment" human performance. In any case, Boudreau argues that, just as continuous change requires a shift in focus from jobs to work elements for purposes of job (re)design, there may need to be an accompanying shift in focus from job engagement to work-element (task) engagement. With this shift comes an opportunity to use work-element engagement as another important factor to consider in making decisions about how to reconfigure jobs. Although Boudreau is optimistic about our ability to apply existing engagement theory to research at the work-elements level, he acknowledges that this can only be determined with new research. Indeed, he poses a variety of interesting research questions about the nature, causes, correlates, and outcomes of engagement when viewed from a work-elements perspective. 
Chapter 9 by Marylène Gagné, Sharon Parker, and Mark Griffin nicely complements the two preceding chapters by providing a theory-based conceptual framework to explain how the changing nature of work might impact employee engagement. The framework involves the integration of existing and emerging theory pertaining to work performance, motivation, and design. The authors begin with the premise that changes in work and the work environment will result in increased uncertainty, changes in the nature of interpersonal relationships, and the introduction of new technologies. Consequently, job performance will need to be reconceptualized to include not only task proficiency, but also adaptability and proactivity as change ensues. Employee engagement can be a key to success for all three components, but the potential effects of change on engagement can be both positive and negative. To explain these effects, Gagné et al. draw on SDT (Deci \& Ryan, 1985; Gagné \& Deci, 2005). First, they identify parallels between the concepts of employee engagement and autonomous motivation, and explain how autonomous motivation is affected by the satisfaction/frustration of three basic psychological needs (autonomy, competence, relatedness). Changes to work and the workplace can serve as a source of both need satisfaction and frustration, leading to increases or decreases in engagement. Finally, the authors draw on the SMART (stimulating, mastery-oriented, agentic, relational, tolerable) theory of work design being developed by Parker and her colleagues to illustrate how work can be (re)designed to increase the likelihood of need satisfaction and enhanced engagement. While grounded in established theory and research, the integrative framework breaks new ground and raises a wealth of important research questions of theoretical and practical relevance.

In Chapter 10, Simon Albrecht proposes a more targeted conceptual framework to link existing theory and research pertaining to organizational change and employee engagement. He notes that, to date, the two issues have largely been studied in isolation, with little cross-fertilization. With the nature, prevalence, and rapidity of change noted in the preceding chapters, it is important to understand how change can affect employee engagement, and how employee engagement might contribute to the effective implementation of change. Central to the conceptual framework is "climate for engagement" and "climate for change" within the organization. Albrecht conceptualizes climate in terms of the perceptions of individuals that team and/or organization members in general are engaged with their work and enthusiastic about change, respectively. In his framework, perceptions of engagement climate are expected to have their strongest and most direct effect on individual employees' own engagement, and perceptions of change climate should have their strongest and most direct effects on individuals' engagement in change. He also notes that cross-over and reciprocal relations are expected. Finally, while 
acknowledging the many other forces in play (see chapters in Part I), Albrecht places particular emphasis on the role of senior leadership in the creation of engagement and change climates. This effort to merge the engagement and change literatures is very timely and raises a plethora of new research questions awaiting answers.

\section{Part III: Research strategies for the new agenda}

Part III of the book provides a change of pace. While the authors of Parts I and II raised a wide range of interesting research questions about engagement, the authors of Part III introduce a set of relatively novel methods and data analytic tools to assist in answering these questions. Of course, they also raise still more interesting research questions that only become apparent once you unearth the tools needed to address them. All of the techniques described in these chapters are complex, and the space available to the authors did not allow them to do complete justice to the details. However, they all do an excellent job of introducing the methods, giving examples of their applications, suggesting how they might be used to address many of the important questions raised in earlier chapters, and, importantly, directing readers to other sources for more detail.

In Chapter 11, William Macey discusses the many different qualitative methods available to engagement researchers as they dig more deeply into the meaning of engagement, the ways it is experienced, how it develops, and the processes by which it influences employees' behavior and well-being. Of course, qualitative methods are not new, but their application by engagement researchers is surprisingly rare. This is curious given that the concept was introduced, at least to the academic community, by Kahn on the basis of qualitative investigations conducted in two quite diverse contexts. Many of the authors in earlier chapters suggest the need for more qualitative research as we begin to grapple with the implications of the changing world of work on employee engagement. Macey identifies a number of the qualitative techniques available for this purpose, along with examples of their application - including several cases involving engagement. Future applications of these techniques to address new questions pertaining to the changing world of work should generate a wealth of information in their own right, as well as raising important questions via inductive reasoning that might be addressed with the advanced quantitative techniques described in the subsequent chapters.

As noted above, much of engagement research has been conducted at the individual level of analysis. That is, it addresses the measurement of engagement in individuals along with the investigation of links between engagement and other variables, including those believed to be antecedents and consequences. 
Indeed, these are the studies serving as the basis for the meta-analytic reviews described previously. Relatively few studies have been conducted at "higher" levels, such as the team, unit, or organization. Thinking about engagement at these levels raises new questions about the measurement of engagement, isomorphism in relations with antecedents and outcomes, and potential interactions across levels of analysis. In Chapter 12, Vicente González-Romá addresses all of these issues and more in a clear, concise, and engaging manner, with illustrative examples and additional sources for more detailed treatments including access to syntax.

In Chapter 13, Sabine Sonnentag, Monika Wiegelmann, and Maike Czink address the related issue of studying dynamic processes in engagement. As researchers begin to study variability (e.g., daily, weekly, seasonal) and changes (gradual or sudden increases or decreases) in engagement, time becomes a level of analysis nested within individuals. Sonnentag et al. explain how the concepts and methods used in multi-level research can be applied to the longitudinal data required to investigate variability and change in engagement. They too provide illustrative examples from the existing literature, describe the available methods and analytic tools available for future research, and direct readers to a wealth of additional resources for more detail on how to apply these methods and tools.

Most engagement research, whether conducted at the individual, unit, or organizational level and within or across time, has been variable-centered. That is, it focuses on how variables relate to one another within a sample. An underlying assumption of the analytic techniques used in this approach is that the parameters identified (e.g., means, variances, path coefficients) apply to the sample as a whole, and to the population from which it was generated. Moreover, the focus remains on the variables of interest (e.g., how does engagement as a variable relate to well-being as a variable?). In Chapter 14, Matthew McLarnon, Alexandre Morin, and David Litalien introduce readers to a complementary set of person-centered data analytic techniques. These person-centered techniques relax the assumption that a single set of parameters can describe a population as a whole, and allow for the possibility that a set of variables might combine differently across subpopulations. As a result, these techniques take a more holistic perspective by focusing on the person rather than the variables. For example, rather than considering how different targets of engagement (e.g., task, job, organization, family) might be related to one another within a population, a person-centered approach allows for the possibility that these engagements with these targets could relate differently to one another (and to other variables) across subpopulations. That is, individuals might have different "engagement profiles." Likewise, there could be 
differences across subpopulations in how one set of variables predicts another or in the trajectories of change in variables over time. McLarnon et al. introduce readers to the many person-centered analytic techniques available, and to the different kinds of questions they can be used to address.

Finally, in Chapter 15 Alexis Fink and William Macey explain how new technologies can provide access to data in quantities not previously imaginable. These data can be qualitative (e.g., web-based text) or quantitative (e.g., human resources information systems data) and can serve as input to the kinds of analyses described in the foregoing chapters. However, given the amount of data potentially available, new techniques for management and analysis are also required. Fink and Macey address these as well. Of course, with availability comes the responsibility to collect and use the data in morally and ethically responsible ways, an issue that Fink and Macey raise up front and continue to promote throughout the chapter. They also raise additional caveats regarding the relevance of the data available (e.g., through data scraping) to constructs of theoretical relevance and or practical value. Indeed, the chapter is a rich source of both possibilities and cautionary notes. This is a field that is arguably more familiar to scholars in the data sciences than to those in the social and management sciences, and is constantly changing. The opportunity seems ripe for collaboration among those in different disciplines to share ideas and expertise so that the best can be made of the vast amount of information that is being generated every day, or should we say every minute or second!

\section{Summary}

This is a book about engagement, and it is intended for new scholars, or those who are simply new to the topic. However, we expect that even the "seasoned" engagement researchers can learn something from the accomplished authors who contributed to this volume. As co-editors, we certainly did! The book provides an overview of what we already know about engagement but, more importantly, it also raises questions that still need to be answered, especially in the face of rapid and extensive changes in the world of work, workers, and working. It also identifies some of the relatively new methods and analytic techniques we can use to answer these questions. We hope you will find it engaging! 


\section{References}

Albrecht, S.L. (Ed.) (2010). Handbook of Employee Engagement: Perspectives, Issues, Research and Practice. Cheltenham, UK, and Northampton, MA, USA: Edward Elgar Publishing.

Bakker, A.B., and Albrecht, S.L. (Eds.) (2018). Work engagement: Current trends. Career Development International, 23(1), 4-11.

Bakker, A.B., and Bal, P.M. (2010). Weekly work engagement and performance: A study among starting teachers. Journal of Occupational and Organizational Psychology, 83, 189-206.

Bakker, A.B., and Demerouti, E. (2007). The job demands-resources model: State of the art. Journal of Managerial Psychology, 22, 309-328.

Bakker, A.B., and Demerouti, E. (2017). Job demands-resources theory: Taking stock and looking forward. Journal of Occupational Health Psychology, 22, 273-285.

Bakker, A.B., Demerouti, E., and Sanz-Vergel, S.I. (2014). Burnout and work engagement: The JD-R approach. Annual Review of Organizational Psychology and Organizational Behavior, 1, 389-411.

Bakker, A., and Leiter, M. (Eds.) (2010). Work Engagement: A Handbook of Essential Theory and Research (pp. 102-117). New York, NY: Psychology Press.

Barrick, M.R., Thurgood, G., Smith, T., and Courtright, S. (2015). Collective organizational engagement: Linking motivational antecedents, strategic implementation, and firm performance. Academy of Management Journal, 58(1), 111-135.

Bledow, R., Schmitt, A., Frese, M., and Kühnel, J. (2011). The affective shift model of work engagement. Journal of Applied Psychology, 96, 1246-1257.

Chan, D. (1998). Functional relations among constructs in the same content domain at different levels of analysis: A typology of composition models. Journal of Applied Psychology, 83(2), 234-246.

Christian, M.S., Garza, A.S., and Slaughter, J.E. (2011). Work engagement: A quantitative review and test of its relations with task and contextual performance. Personnel Psychology, 64, 89-136.

Costa, P., Passos, A.M., and Bakker, A.B. (2014a). Team work engagement: A model of emergence. Journal of Occupational and Organizational Psychology, 87, 414-436.

Costa, P., Passos, A.M., and Bakker, A.B. (2014b). Empirical validation of the team work engagement construct. Journal of Personnel Psychology, 13, 34-45.

Crawford, E.R., LePine, J., and Rich, B.L. (2010). Linking job demands and resources to employee engagement and burnout: A theoretical extension and meta-analytic test. Journal of Applied Psychology, 95, 834-848.

Deci, E. L., and Ryan, R. M. (1985). Intrinsic Motivation and Self-Determination in Human Behavior. New York, NY: Plenum Press.

Deci, E.L., and Ryan, R.M. (2000). The "what" and "why" of goal pursuits: Human needs and the self-determination of behavior. Psychological Inquiry, 11, 227-268.

Demerouti, E., Bakker, A.B., Nachreiner, F., and Schaufeli, W.B. (2001). The job demands-resources model of burnout. Journal of Applied Psychology, 86(3), 499-512.

Gagné, M., and Deci, E.L. (2005). Self-determination theory and work motivation. Journal of Organizational Behavior, 26, 331-362.

Halbesleben, J.R.B. (2010). A meta-analysis of work engagement: Relationships with burnout, demands, resources, and consequences. In A.B. Bakker and M.P. Leiter (Eds.), Work Engagement: A Handbook of Essential Theory and Research (pp. 102-117). New York, NY: Psychology Press. 
Harter, J.K., Schmidt, F.L., Agrawal, S., Plowman, S.K., and Blue, A.T. (2020). Increased business value for positive job attitudes during economic recessions: A meta-analysis and SEM analysis. Human Performance, 33(4), 307-330.

Harter, J.K., Schmidt, F.L., and Hayes, T.L. (2002). Business-unit level relationship between employee satisfaction, employee engagement, and business outcomes: A meta-analysis. Journal of Applied Psychology, 87, 268-279.

Hobfoll, S.E. (1989). Conservation of resources: A new attempt at conceptualizing stress. American Psychologist, 44, 513-524.

Kahn, W.A. (1990). Psychological conditions of personal engagement and disengagement at work. Academy of Management Journal, 33, 692-724.

Knight, C., Patterson, M., and Dawson, J. (2016). Building work engagement: A systematic review and meta-analysis investigating the effectiveness of work engagement interventions. Journal of Organizational Behavior, 38(6), 790-812.

Macey, W.H., and Schneider, B. (2008). The meaning of employee engagement. Industrial and Organizational Psychology: Perspectives on Science and Practice, 1, 3-30.

Mackay, M., Allen, J.A., and Landis, R.S. (2017). Investigating the incremental validity of employee engagement in the prediction of employee effectiveness: A meta-analytic path analysis. Human Resource Management Review, 27, 108-120.

May, D.R., Gilson, R.L., and Harter, L.M. (2004). The psychological conditions of meaningfulness, safety and availability and the engagement of the human spirit at work. Journal of Occupational and Organizational Psychology, 77, 11-37.

Meyer, J.P. (2013). The science-practice gap and employee engagement: It's a matter of principle. Canadian Psychology, 54, 235-245.

Meyer, J.P. (2017). Has employee engagement had its day: What's next and does it matter? Organizational Dynamics, 46, 87-95.

Meyer, J.P., Gagné, M., and Parfyonova, N.M. (2010). Toward an evidence-based model of engagement: What we can learn from motivation and commitment research. In S. Albrecht (Ed.), Handbook of Employee Engagement: Perspectives, Issues, Research and Practice (pp. 62-73). Cheltenham, UK, and Northampton, MA, USA: Edwin Elgar Publishing.

Newman, D.A., Joseph, D.L., and Hulin, C.L. (2010). Job attitudes and employee engagement: Considering the attitude "A-factor." In S.L. Albrecht (Ed.), Handbook of Employee Engagement: Perspectives, Issues, Research and Practice (pp. 43-61). Cheltenham, UK, and Northampton, MA, USA: Edward Elgar Publishing.

Rich, B.L., LePine, J.A., and Crawford, E.R. (2010). Job engagement: Antecedents and effects of job performance. Academy of Management Journal, 53, 617-635.

Rothbard, N.P. (2001). Enriching or depleting: The dynamics of engagement in work and family roles. Administrative Science Quarterly, 46, 655-684.

Saks, A.M. (2006). Antecedents and consequences of employee engagement. Journal of Managerial Psychology, 21, 600-619.

Saks, A.M., and Gruman, J.A. (2014). What do we really know about employee engagement? Human Resource Development Quarterly, 25, 155-182.

Salanova, M., Llorens, S., Cifre, E., and Martínez, I.M. (2012). We need a hero! Towards a validation of the HEalthy \& Resilient Organization (HERO) Model. Group \& Organization Management, 37(6), 785-822.

Schaufeli, W.B., and Bakker, A.B. (2004). Job demands, job resources, and their relationship with burnout and engagement: A multi-sample study. Journal of Organizational Behavior, 25(3), 293-315. 
Schaufeli, W.B., Salanova, M., González-Romá, V., and Bakker, A.B. (2002). The measurement of engagement and burnout: A two sample confirmatory factor analytic approach. Journal of Happiness Studies, 3, 71-92.

Schaufeli, W.B., and Taris, T.W. (2014). A critical review of the job demands-resources model: Implications for improving work and health. In G. Bauer and O. Hamming (Eds.), Bridging Occupational, Organizational and Public Health (pp. 43-68). Dordrecht: Springer.

Schneider, B., Yost, A., Kropp, A., Kind, C., and Lam, H. (2017). Workforce engagement: What it is, what drives it, and why it matters for organizational performance. Journal of Organizational Behavior, 39, 462-480.

Seligman, M.E.P., and Csikszentmihalyi, M. (2000). Positive psychology: An introduction. American Psychologist, 55(1), 5-14.

Seligman, M.E.P., and Csikszentmihalyi, M. (2014). Positive psychology: An introduction. In M. Csikszentmihalyi (Ed.), Flow and the Foundations of Positive Psychology (pp. 279-298). New York, NY: Springer US.

Shantz, A. (Ed.) (2017). Coming full circle: Putting engagement into practice. Organizational Dynamics, 46, 65-66.

Sonnentag, S. (2003). Recovery, work engagement, and proactive behavior: A new look at the interface between nonwork and work. Journal of Applied Psychology, 88, 518-528.

Truss, C., Delbridge, R., Alfes, K., Shantz, A., and Soane, E. (Eds.) (2009). Employee Engagement in Theory and Practice. London: Routledge.

Young, H.R., Glerum, D.R., Wang, W., and Joseph, D.L. (2018). Who are the most engaged at work? A meta-analysis of personality and employee engagement. Journal of Organizational Behavior, 39, 1330-1346. 
John P. Meyer and Benjamin Schneider - 9781789907858 Downloaded from PubFactory at 04/26/2023 10:55:17AM via free access 